\title{
DO VAZIO URBANO PÚBLICO À FINANCEIRIZAÇÃO PRIVADA: COMO O PATRIMÔNIO DA UFRJ RESPONDERÁ AO CAOS FINANCEIRO
}

FROM PUBLIC URBAN VOID TO PRIVATE FINANCING: HOW UFRJ ASSETS WILL RESPOND TO THE FINANCIAL CHAOS

\section{RESUMO}

A forma de manejar a propriedade imobiliária vem se reconfigurando desde a década de 1990 por meio de um processo de financeirização que, atualmente, resulta na transformação da sua natureza original e repercute na produção do espaço urbano. A perspectiva deste estudo parte da análise de que a ociosidade imobiliária corresponde a um dos fenômenos urbanos que estimulam esse tratamento fundiário, e ao mesmo passo, observa-se a crescente possibilidade do mercado imobiliário explorar economicamente uma fatia ociosa e valorizada do tecido urbano, qual seja, o patrimônio das universidades federais. A exemplo disto, este estudo discute a iminente financeirização do patrimônio da Universidade Federal do Rio de Janeiro, recentemente publicizado por edital de licitação do Banco Nacional do Desenvolvimento Econômico e Social. Desta forma, a partir de uma análise empírica realiza-se um breve, mas instigante estudo de caso da forma de manejo do patrimônio daquela universidade correlacionando seus imóveis ociosos à problemática inicialmente apontada.

Palavras-chave: Vazio urbano; produção do espaço urbano; Financeirização da propriedade pública; patrimônio da UFRJ.

\section{ABSTRACT}

The way to manage real estate has been reconfiguring since the 1990's through a financialization process that currently results in the transformation of its original nature and repercussions on the production of urban space. The perspective of this study starts from the analysis that real estate idleness corresponds to one of the urban phenomena that stimulate this land treatment, and at the same time, it is observed the growing possibility of the real estate market to economically exploit an idle and valued slice of the urban fabric, which means that is, the heritage of federal universities. As an example of this, this study discusses the imminent financialization of the patrimony of the Federal University of Rio de Janeiro, recently published by bidding notice of the National Bank of Economic and Social Development. Thus, based on an empirical analysis, a brief but thought-provoking case study of the management of the heritage of that university is carried out, correlating its idle properties with the problem initially pointed out.

Keywords: Urban void; production of urban space; Financialization of public property; UFRJ's patrimony.

\section{Carmem Matos ${ }^{\text {a }}$ \\ (D) Felipe Jardim ${ }^{a}$}

a Universidade do Estado do Rio de Janeiro (UERJ), Rio de Janeiro, RJ, Brasil

DOI: $10.12957 /$ geouerj.2020.47274

Correpondência: carmemsilviamatos@hotmail.com

Recebido em: 15 set. 2019

Revisado em: 23 out. 2019

Aceito em: 13 dez.2019 


\section{INTRODUÇÃO}

No contexto da política urbana percebe-se que a propriedade pública recebe um tratamento que não possui um viés puramente jurídico, partindo-se da ideia de que a forma de utilizá-la perpassa por uma discussão de fundo econômico e financeiro, tanto que a possibilidade de financeirização do patrimônio imobiliário em um fundo de investimento está legalmente disposto.

Essa prática fundiária se traduz pela inserção de diversos instrumentos financeiros ligados ao aspecto econômico da dinâmica da produção do espaço urbano. O entrelaçamento entre as dimensões do urbanismo e das atividades econômica e financeira são evidentes e influenciam na forma de manejar a propriedade urbana, inclusive a pública, no sentido de reproduzir uma lógica de mercado vinculada a rapidez das trocas imobiliárias que destoa da natureza imóvel daquela propriedade.

Nos últimos anos, a política de austeridade praticada pelo governo federal vem estrangulando cada vez mais a possibilidade de manutenção das universidades federais com violenta restrição orçamentária. O que aparentemente poderia expressar a execução de uma linha dura da economia sob a justificativa de contenção dos gastos públicos, revela-se mais como um projeto de desmonte da educação superior pública a fim de contemplar a lógica de mercado, que por sua vez, anteviu nesse segmento um nicho de exploração econômica rentável.

Isso se verifica pelo sucateamento dos equipamentos universitários, diminuição de incentivos à pesquisa e à extensão, desvalorização do corpo docente e cortes de benefícios de permanência estudantil, amplamente divulgado pela mídia, ao passo que, por outro lado, concomitantemente, ocorre o fortalecimento das ações e lucros de grandes grupos educacionais.

Neste diapasão, surge a possibilidade de financeirizar o espaço universitário para fins de exploração econômica, sob a justificativa de que esta seria uma alternativa à sua manutenção, que é o caso do projeto piloto conferido ao patrimônio imobiliário da Universidade Federal do Rio de Janeiro (UFRJ) por meio de edital de licitação AARH no 31/2018 publicado pelo Banco Nacional de Desenvolvimento Econômico e Social (BNDES).

Como será discutido, parte do espaço público da UFRJ parece ter sido diagnosticado como não funcional sob as três dimensões existentes: não edificado, não utilizado e subutilizado. Este patrimônio foi vulnerabilizado a tal ponto que o tratamento sugerido ao seu colapso seria a realização do oposto à sua natureza, qual seja, a exploração econômica do seu espaço a fim de obtenção de lucro.

A fim de desenvolver o tema, este artigo está estruturado em três partes, sendo a primeira esta introdução; a segunda apresenta um estudo sobre a reconfiguração da propriedade imobiliária a partir da sua financeirização; a terceira discute o processo de financeirização dos ativos imobiliários da UFRJ deflagrado 
pelo edital AARH no 31/2018 BNDES, apresentando uma pesquisa empírica que busca correlacionar os imóveis ociosos da Universidade ao seu processo de financeirização.

\section{A RECONFIGURAÇÃO DA PROPRIEDADE IMOBILIÁRIA}

A tônica das transformações ocorridas na propriedade imobiliária constituiu-se fundamentalmente pela ampliação da mobilidade do capital no espaço, alterando-se qualitativamente a sua forma ao permitir que ativos econômicos fixos e com pouca liquidez pudessem ser mais amplamente incorporados à circulação do capital. Seria a criação de liquidez a partir da fixidez do espaço.

O processo de abstração jurídica da propriedade alimenta a dissociação progressiva entre valor de uso e valor de troca, uma vez que transforma a terra em algo equiparável a um título de capital fictício.

Segundo Harvey (2006), finanças e propriedade imobiliária articulam-se de forma cognitiva e funcional, sendo que na primeira a propriedade imobiliária passa a funcionar como um ativo que confere ao seu proprietário uma expectativa de rendimento, desta forma, assimila-se a uma ação que representa para seu titular a possibilidade de apropriar-se de uma parte dos resultados da empresa sob a forma de dividendos.

Nesta ótica, o direito de monopólio sobre um fragmento do espaço representa para seu proprietário a expectativa de se apropriar de um determinado montante da riqueza socialmente produzida sob a forma de renda.

Assim, a propriedade imobiliária passa a ser um investimento como outro qualquer, e a renda que ela proporciona é assimilada como remuneração do capital adiantado pela compra do imóvel rentável.

A dimensão funcional está ligada ao fato da produção do espaço em um contexto em que a produção do espaço emergir como um elemento fundamental para a valorização do capital financeiro que se articula à propriedade imobiliária fazendo com que esta adquira novas formas, logo, uma massa crescente de ativos financeiros passa a ter seu conteúdo econômico lastreado em imóveis e os direitos de propriedade que incidem sobre eles passam a assumir progressivamente a forma de ativos financeiros.

O produto imobiliário é constituído por edificação e terra, aquela se traduz como mercadoria quantificada pelo trabalho socialmente necessário para produzi-la, sendo um objeto portador de valor. A terra, por sua vez, não é fruto do trabalho, nem objeto portador de valor. Diferentemente das edificações, ela não se desgasta ao longo do tempo, não sofrendo desvalorização (entendendo-se tal expressão como a deterioração do trabalho incorporado às mercadorias). 
Isso não significa, obviamente, que ela está livre de precificação, mas, precisamente por não ser fruto do trabalho humano e, consequentemente, não se submeter a mensurações econômicas em função do tempo de trabalho socialmente necessário para produzi-la, Polanyi (1944) a caracterizou como uma mercadoria fictícia. A propriedade privada da terra, então, sob este prisma, constitui-se como monopólio sobre um fragmento do espaço que confere o direito de apropriação de uma parcela da riqueza socialmente produzida como contrapartida ao consentimento de uso.

Diferente do valor de uso da terra, em um contexto onde as relações sociais de produção se estabelecem sob a forma capitalista, o preço da terra é determinado em função das expectativas de apropriação futura de renda fundiária, e o imóvel, por sua vez, é precificado pela combinação de dois componentes distintos, o valor incorporado à construção e a renda capitalizada na propriedade da terra (PEREIRA, 2015).

Apesar dessas semelhanças, a propriedade fundiária e os títulos de capital fictício apresentam características próprias que os diferenciam, uma vez que, as formas abstratas de riqueza têm um caráter intrinsecamente volátil, o que pode levar tanto a aceleração quanto a depreciação abrupta dos ativos financeiros.

O preço da terra, contudo, apesar de poder sofrer variações significativas em razão de fatores como, as transformações nos padrões urbanísticos locais, mudanças na conjuntura econômica, entre outros, a concretude desse ativo econômico, que representa o monopólio sobre um fragmento do espaço, permite a apropriação de riqueza em bases mais estáveis do que os títulos de capital fictício. Isso torna a propriedade fundiária um dos mais importantes dispositivos de reserva de valor, perpetuando a sua financeirização e exercendo papel-chave na preservação de patrimônios (BOLAFFI, 1982).

Em virtude dos atributos específicos da propriedade fundiária que faltam às formas abstratas de riqueza, aquela vem sendo progressivamente acionada como lastro de valor destas, provocando uma simbiose entre ambas que subordina progressivamente a produção do espaço a uma lógica financeira.

Para que esta dinâmica prevaleça torna-se necessária a criação de condições adequadas à obtenção de renda, para isso combinam-se processos com ganhos de natureza especulativa proporcionados por uma articulação crescente entre movimentos do capital e ações do Estado.

Nesse contexto, a movimentação estratégica do capital no espaço torna-se um fator determinante da dinâmica dos processos de urbanização, submetendo-os progressivamente a uma lógica orientada para impulsionar processos de valorização de magnitude e velocidade compatíveis com as exigências do capital financeiro (PEREIRA, 2015). 
A articulação entre a valorização do capital fictício e a produção do espaço exige a criação de artifícios jurídicos que estabeleçam condições propícias à circulação do capital no espaço. Desta forma, proliferam-se instrumentos financeiros de base imobiliária com características distintas da propriedade convencional, sendo concebidos de modo a permitir que os investimentos no espaço construído tenham liquidez, possam ser submetidos a procedimentos padronizados de mensuração de risco, proporcionem segurança jurídica a credores, entre outras exigências.

Assim, o processo de abstração da propriedade é impulsionado levando ao surgimento de operações complexas de divisão e reagrupamento de direitos e obrigações associados a transações imobiliárias. Com o intuito de contextualizar essa dinâmica regulatória frente ao dinamismo imobiliário, passa-se a analisar a atuação do Direito frente ao processo de financeirização da propriedade.

\section{A reforma do marco regulatório da propriedade e do financiamento imobiliário}

A regulação da propriedade e do financiamento imobiliário no Brasil passou por um processo de reestruturação abrangente a partir dos anos 1990. Os principais marcos legais desse processo foram: a Lei $\mathrm{n}^{\circ}$ 8.668, de 25 de junho de 1993, que introduziu os Fundos de Investimento Imobiliário (FIls) no ordenamento jurídico do país; a Lei n ${ }^{\circ}$ 9.514, de 20 de novembro de 1997, que criou o Sistema Financeiro Imobiliário (SFI) e disciplinou os contratos de alienação fiduciária de bens imóveis; a Lei ${ }^{\circ} 10.931$, de 2 de agosto de 2004, que ampliou o rol de instrumentos financeiros de base imobiliária que integravam o SFI e disciplinou o instituto do patrimônio de afetação em incorporações imobiliárias; e também um conjunto de dispositivos legais esparsos que concederam benefícios fiscais a investimentos feitos nos títulos financeiros de base imobiliária criados nesse contexto.

Esse conjunto de mecanismos de proteção a credores ajudou a difundir uma percepção de que os investimentos em ativos imobiliários - tanto os investimentos feitos diretamente como aqueles feitos por intermédio de títulos financeiros de base imobiliária - eram transações econômicas razoavelmente seguras, contribuindo para a criação de um ambiente favorável para a ampliação do volume do financiamento imobiliário no país (ROYER, 2009; FIX, 2011; SANFELICI, 2013).

Essa reestruturação jurídica encontrou respaldo nos agentes econômicos que diagnosticavam como limitada a capacidade de financiamento dos fundos governamentais e dos bancos, argumentando pela necessidade em estabelecer formas alternativas de captação de recursos por meio de operações de mercado de capitais. A defesa de instrumentos do mercado de capitais apoiou-se na premissa de que, em algum momento, as principais fontes de recurso para o financiamento imobiliário - o Fundo de Garantia do Tempo 
de Serviço (FGTS) e o Sistema Brasileiro de Poupança e Empréstimo (SBPE) - iriam se tornar insuficientes para atender à demanda por crédito no país. ${ }^{1}$

Além disso, de forma ambígua, abria um leque de justificativas à criação desses instrumentos, que ora beneficiaria empreendimentos comerciais e residenciais voltados ao público de maior renda, ora como uma forma de captação de recursos para o financiamento imobiliário em geral que impulsionaria também a produção privada de moradia para a população de baixa renda.

O primeiro argumento em defesa da ampliação da oferta de recursos ao financiamento imobiliário em geral, decorria, principalmente, da crença na existência de uma correlação positiva entre o volume das atividades de produção imobiliária e o crescimento econômico² ${ }^{2}$ E ainda, na suposição de que isso também se traduziria em maior oferta de moradia popular (PEREIRA, 2015).

A produção privada de moradia popular, no entanto, funcionaria mais como um elemento de consenso para justificar medidas como incentivos fiscais e outras formas de estímulo.

Cabe ainda destacar, que a falta de definição entre financiamento imobiliário e crédito habitacional abriu margem, por exemplo, para que operações realizadas no âmbito do SFI fossem incluídas como crédito habitacional pelas instituições integrantes do SFH, e assim, ao invés de ampliar a oferta de crédito para o financiamento de moradia popular, possibilitou ao SFI a drenagem de recursos dos fundos públicos teoricamente destinados a essa finalidade, agindo como um dispositivo de transferência de linhas de crédito subvencionadas para a promoção de empreendimentos de mercado (ROYER, 2009).

Embora existisse a afirmação recorrente de que um dos objetivos por trás da criação do SFI era a transferência do sistema bancário para o mercado de capitais o centro gravitacional do financiamento imobiliário, nem todas as mudanças efetivamente ocorridas nesse contexto seguiram essa direção.

A exemplo disto, cita-se a Letra de Crédito Imobiliário (LCI), instrumento de captação imobiliária do SFI que gerou maior volume de emissões, reafirmando a centralidade das instituições bancárias no financiamento

\footnotetext{
${ }^{1}$ Antes da criação do SFI, o financiamento imobiliário no país baseava-se, sobretudo, no crédito direcionado ao setor pelo FGTS e pelo SBPE, que integram o Sistema Financeiro da Habitação (SFH). As operações financiadas com esses recursos, ainda hoje as principais fontes de crédito imobiliário no país (ROYER, 2009; ELOY, 2013), destinam-se majoritariamente ao segmento residencial. Além disso, são limitadas por critérios de faixa de renda dos destinatários e de valor individual das unidades produzidas. No caso do FGTS, os recursos captados são destinados ao financiamento habitacional dentro das faixas de renda do SFH, e também a investimentos em saneamento básico e infraestrutura urbana. No caso do SBPE, 65\% dos recursos captados devem ser direcionados ao financiamento de imóveis no setor residencial, sendo que $80 \%$ desse montante ( $52 \%$ do total d recursos captados) devem ser direcionados a imóveis que se enquadrem nos parâmetros do SFH.

2 Nesse sentido, o diretor da corretora de valores mobiliários entrevistado por Álvaro Pereira (2015) ressalta que, "sob a ótica macroeconômica", o incentivo e o desenvolvimento da indústria imobiliária afeta toda a geração de riqueza no país". O entrevistado explica que o setor imobiliário "tem uma cadeia produtiva extremamente complexa que gera uma riqueza gigante para o país, gera emprego diretamente, absorve mão de obra não especializada", o que faz com que seja "extremamente vantajoso para a economia de qualquer país, especialmente da nossa, que é uma economia muito frágil".
} 
imobiliário no país. Isso mostra que a alegada preferência pelo mercado de capitais é antes um discurso ideológico de alguns agentes envolvidos nesse debate do que uma tendência efetiva do recente processo de mudança ocorrido nos padrões do financiamento imobiliário no Brasil (PEREIRA, 2015).

Por outro lado, em que pese a centralidade do sistema bancário em relação ao financiamento imobiliário, evidencia-se a possibilidade de financeirização de imóveis por meio da constituição de fundos de investimento imobiliário cuja alocação de recursos é protagonizada pelo mercado de capitais. Esse mecanismo financeiro apresenta-se como um dos objetivos do edital AARH no 31/2018 do BNDES para manejar os ativos imobiliários da UFRJ. Em razão disto, segue-se adiante uma breve análise sobre fundos de investimento imobiliários.

\section{Fundos de Investimento Imobiliários}

Os fundos de investimentos consistem em uma forma de alocação de recursos captados no mercado para aplicação nos mais variados investimentos e segmentos a partir de ações negociadas na bolsa de valores brasileira, cotas de sociedades limitadas, imóveis, recebíveis mercantis e outros créditos dos mais variados.

Possuem natureza de condomínio, portanto, há uma propriedade comum entre os diversos condôminos (cotistas), sendo que cada um possui o domínio de uma fração ideal da totalidade dos bens que corresponde à sua parte proporcional em relação ao montante investido no fundo (cotas).

São representados pelo administrador ${ }^{3}$ que atua em nome próprio e em benefício do fundo, divididos em cotas detidas pelos investidores (cotistas). Em razão de sua natureza condominial há uma propriedade comum entre os diversos condôminos (cotistas), sendo que cada um possui o domínio de uma fração ideal da totalidade dos bens que corresponde à sua parte proporcional em relação ao montante investido no fundo (cotas).

Os Fundos de Investimento Imobiliários (FII) foram introduzidos no ordenamento jurídico brasileiro pela Lei no 8.668, de 25 de junho de 1993, com o objetivo de distribuir cotas por intermédio do sistema de distribuição de valores mobiliários, a fim de ampliar a abrangência do mercado imobiliário ao permitir a inclusão de pequenos investidores que, usualmente, não teriam condições de investir isoladamente em ativos imobiliários.

\footnotetext{
3 "Art. 80. O administrador, observadas as limitações legais e as previstas nesta Instrução, tem poderes para praticar todos os atos necessários ao funcionamento do fundo de investimento, sendo responsável pela constituição do fundo e pela prestação de informações à CVM na forma desta Instrução e quando solicitado." Somente pode ser administrador de FIl sociedade que seja banco múltiplo com carteira de investimento ou com carteira de crédito imobiliário, banco de investimento, sociedade de crédito imobiliário, sociedade corretora ou sociedade distribuidora de títulos e valores mobiliários, ou outras entidades legalmente equiparadas.
} 
A Lei no 8.688/93 estabeleceu algumas características básicas para os FII, tais como: i) obrigatoriedade de organização como fundo de investimento fechado, não permitem o resgate das suas cotas pelos cotistas, podendo esses investidores, no entanto, negociá-las no mercado secundário; (ii) objeto específico de investimento em empreendimentos imobiliários; (iii) natureza jurídica do fundo de investimento como um condomínio especial, sem personalidade jurídica, porém, com limitação de responsabilidade para os cotista; e (iv) divisão do seu patrimônio em cotas definidas como valores mobiliários, portanto regulados pela CVM.

Por se constituírem exclusivamente como fundos de investimento fechado, suas cotas não são resgatáveis livremente, a não ser ao término do seu prazo de duração. Essa característica legal decorre diretamente da ausência de liquidez inerente aos imóveis que impede a sua rápida alienação e, consequentemente o retorno imediato do investimento do cotista. Sendo assim, atribui-se natureza fechada aos Fll a fim de que não seja solicitado o resgate de antecipado decotas.

O condomínio estabelecido pelo Fll é de regime especial e não possui personalidade jurídica, portanto não está apto a contrair direitos e obrigações dependendo, para isso, do administrador que, obrigatoriamente, tem que ser: sociedade de banco múltiplo com carteira de investimento ou de crédito imobiliário, banco de investimento, sociedade de crédito imobiliário, sociedade corretora ou sociedade distribuidora de títulos e valores mobiliários, ou ainda, outras entidades legalmente equiparadas.

Em função desses aspectos, e ainda, da necessidade de transcrição no Registro Geral de Imóveis (RGI) para a aquisição de bens imóveis, a Lei no $8.668 / 93^{4}$ determina no seu artigo 6o que a administradora é proprietária dos bens do FII, em caráter fiduciário, e sendo assim, figura como titular no Registro de Imóveis competente. E neste compasso, evita-se que dívidas das instituições administradoras dos FII recaiam sobre os ativos pertencentes ao fundo, a Lei no 8.668/93 prevê expressamente que os bens e direitos integrantes do patrimônio dos FII não se comunicam com o patrimônio da instituição administradora.

Pelo exposto, percebe-se a articulação da atividade econômica e financeira e sua regulação no sentido de encontrar mecanismos de tratar a propriedade imobiliária como um ativo financeiro ao vinculá-la a valores mobiliários negociáveis no mercado de capitais, retirando, com isso, potencialidades ligadas ao valor de uso mais afetas à natureza imóvel dessa propriedade.

\footnotetext{
4 “Art. 60 O patrimônio do Fundo será constituído pelos bens e direitos adquiridos pela instituição administradora, em caráter fiduciário.

Art. 7ํㅡ Os bens e direitos integrantes do patrimônio do Fundo de Investimento Imobiliário, em especial os bens imóveis mantidos sob a propriedade fiduciária da instituição administradora, bem como seus frutos e rendimentos, não se comunicam com o patrimônio desta, observadas, quanto a tais bens e direitos, as seguintes restrições: I - não integrem o ativo da administradora; II - não respondam direta ou indiretamente por qualquer obrigação da instituição administradora; III - não componham a lista de bens e direitos da administradora, para efeito de liquidação judicial ou extrajudicial; IV - não possam ser dados em garantia de débito de operação da instituição administradora; $V$ - não sejam passíveis de execução por quaisquer credores da administradora, por mais privilegiados que possam ser; $\mathrm{VI}$ - não possam ser constituídos quaisquer ônus reais sobre os imóveis."
} 
Mais especificamente com relação ao caso da UFRJ, a exploração econômica do seu patrimônio está entregue a uma versão objetiva e mercadológica em "bloco", a partir de um modelo de projeto que não precisará considerar o ambiente acadêmico em si, mas sim, voltar-se-á, exclusivamente, aos investidores e seus intuitos de lucro.

A Universidade, por sua vez, diante da grave crise financeira que enfrenta, provavelmente, não representa uma parte totalmente livre para negociar uma tratativa desse porte, restando o risco de comprometer-se com a lógica da financeirização e submeter-se a uma saída pouco produtiva à sua autonomia universitária e situação financeira.

O próximo capítulo tratará da possibilidade de financeirização do patrimônio da UFRJ por meio da análise do edital já referido. Apresentará também uma quantidade expressiva de imóveis ociosos, identificados não de forma exaustiva, que compõem o patrimônio da Universidade, e com isso, buscar correlacionar a proposta de financeirização com a produção desses vazios urbanos.

\section{A FINANCEIRIZAÇÃO DO PATRIMÔNIO DA UFRJ}

Em 13 de julho de 2018 foi publicado um edital ${ }^{5}$ pelo Banco Nacional de Desenvolvimento Econômico e Social (BNDES), com o objetivo de contratar, por licitação na modalidade pregão, serviços técnicos à implantação de outorga de concessão de uso e/ou constituição de fundo de investimento imobiliário de ativos imobiliários da Universidade Federal do Rio de janeiro - UFRJ.

Tais serviços técnicos seriam direcionados à realização de um estudo prévio acerca dos ativos imobiliários situados na Cidade Universitária, Centro e Praia Vermelha, composto por, pelo menos, 10 vazios urbanos (Figura 1), cerca de 430 mil metros quadrados (SCHIMIDT, 2019).

\footnotetext{
5 Pregão Eletrônico AARH no 31/2018 - BNDES. Disponível em: <www.bndes.gov.br>.
} 
Figura 1. Localização de 10 imóveis ociosos passíveis de financeirização. Fonte: SCHIMIDT, 2018 (adaptado).

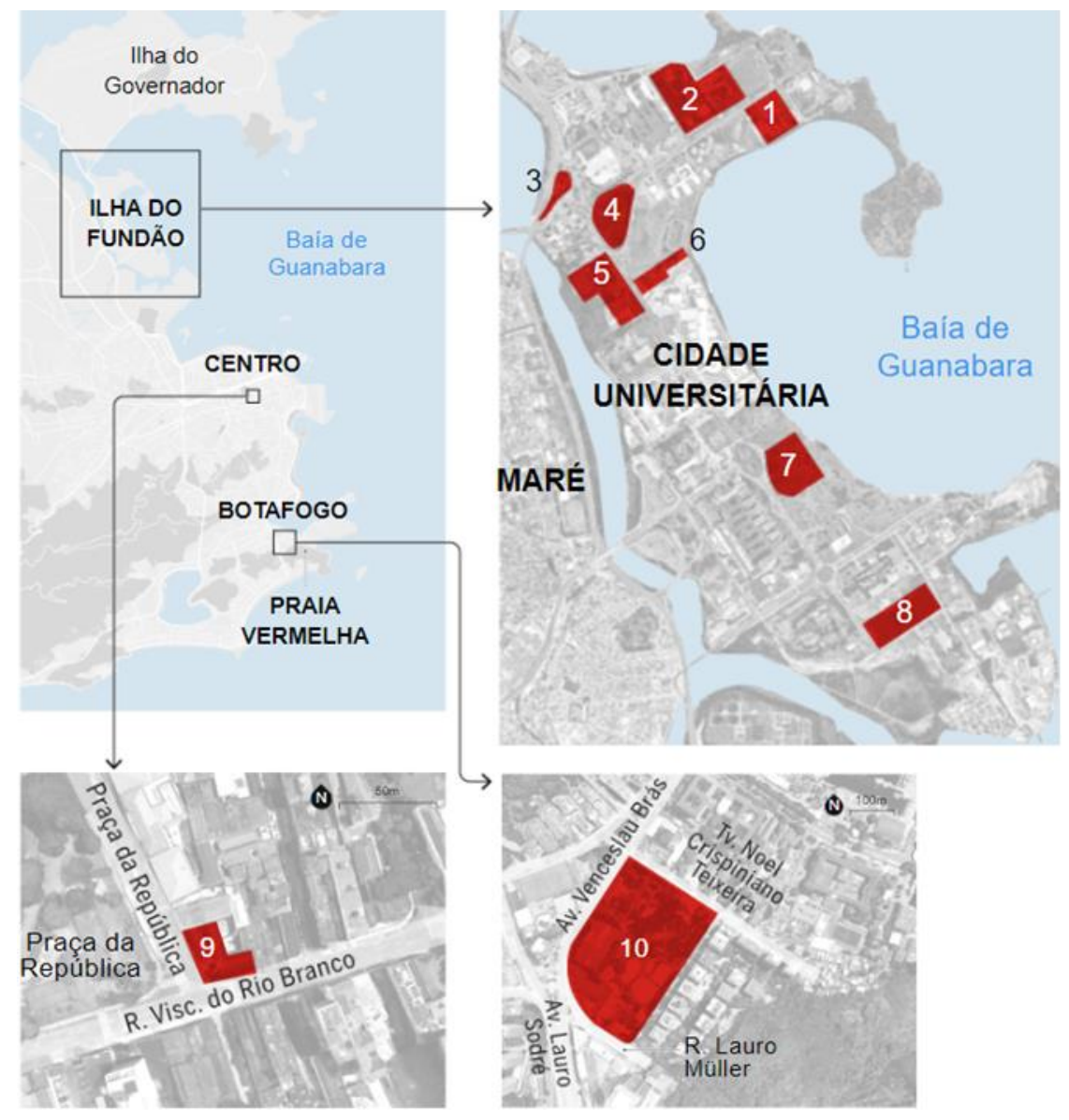

Esse projeto é tratado no edital como uma valorização dos ativos imobiliários da UFRJ que teria o condão de criar contrapartidas de investimentos em infraestrutura, ou seja, deflui-se dessa narrativa que os imóveis da Universidade, em parte, estariam sofrendo de algum nível de ociosidade imobiliária que deveria se ajustar a uma melhor funcionalidade.

Sendo assim, a justificativa para financeirizar esse patrimônio guarda relação direta com a provocação dos vazios urbanos produzidos naquele espaço, que, aliados a gravíssima questão financeira suscitada pelos cortes de recursos formou o pacote de exploração econômica como alternativa mantenedora da instituição.

Desse ponto de vista, percebe-se a vulnerabilidade fundiária causada pelos vazios urbanos que levam a perpetuar os mecanismos de exploração e acumulação da lógica de mercado. Trata-se da manipulação da terra urbana pública que cria formas de transferir para a iniciativa privada sua gestão, a fim, é claro, de alimentar os irredutíveis lucros do mercado, agora financeirizados e amplamente circuláveis a despeito da natureza pública e imóvel do patrimônio. 
Logo, a ociosidade imobiliária não só estimula como acelera os processos de acumulação do capitalismo. Deixam a deriva parcelas de território que facilmente são cooptadas à exploração econômica, neste caso especificamente, nem se fala em projeto de pesquisa, extensão, aperfeiçoamento docente, bolsas de incentivo ou qualquer fomento à educação superior em si, tratando-se apenas do aspecto econômico e de infraestrutura.

Nesta linha mercadológica, o edital não apresenta nenhuma previsão de receita financeira à Instituição, apenas, a possibilidade de uma contrapartida em infraestrutura, isto é, restaurantes universitários, laboratórios e outros equipamentos, a partir de um modelo de gestão de recursos que asseguraria a aplicação dos recursos financeiros e não financeiros, oriundos de outorga da concessão de uso ou dos lucros das cotas do fundo de investimento imobiliário, em projetos de investimento.

O projeto é piloto, não existe outro caso no país, mas que pode chegar a ser consagrado nacionalmente, visto que não raro as universidades federais e estaduais possuem patrimônio ocioso.

Segundo o edital, entende-se por concessão de uso, a transferência onerosa, por período determinado, mediante licitação, do direito de construção, conservação, manutenção, reforma, ampliação ou melhoramento, para o aproveitamento econômico dos ativos imobiliários da universidade, por conta e risco do concessionário, e ativos imobiliários os bens imóveis (terrenos e edificações) de propriedade da universidade, que serão objeto de análise para futuro aproveitamento econômico.

Fundo de investimento imobiliário seria a comunhão de recursos captados por meio do sistema de distribuição de valores mobiliários e destinados à aplicação em empreendimentos imobiliários, criado pela Lei no 8.668/93, e regulamentado pelas Instruções CVM no 400, de 29 de dezembro de 2003, no 472, de 31 de outubro de 2008 e no 571, de 25 de novembro de 2015 - como já esclarecido no tópico 2.2.

Em outros termos, isto significa transformar a natureza imobiliária do patrimônio da UFRJ em mobiliária, por meio da transferência de seus bens imóveis à Constituição de um fundo de investimento privado representado por cotas, as quais, por sua vez, serão negociadas pelo sistema de distribuição de valores mobiliários.

A fim de analisar os ativos imobiliários da Cidade Universitária, o edital prevê a apresentação de um masterplan que deve contemplar todos os seus ativos imobiliários, indicando usos, ocupações, descrição e inventário dos ativos imobiliários, projeto conceitual com "mix de empreendimentos" que representaria a alocação ótima do(s) empreendimento(s) imobiliário(s) a ser(em) desenvolvido(s) em cada um dos ativos imobiliários da universidade; análise do mercado imobiliário na região e/ou de empreendimentos semelhantes aos que poderão ser desenvolvidos. 
A formatação final do projeto se iniciará após a decisão, pela universidade, sobre o modelo de cessão e contrapartidas a ser adotado para o aproveitamento econômico dos ativos imobiliários, de forma a indicar os valores econômicos, os parâmetros, as premissas e o(s) instrumento(s) contratual(is) adequado(s) à realização do mesmo.

Após a apresentação de conteúdos importantes do edital, buscar-se demonstrar, por meio de pesquisa empírica, a ideia de que a produção de vazios urbanos no espaço territorial da UFRJ contribuiu para o seu processo de financeirização do seu patrimônio. Desta forma, a partir de agora apresenta-se o que foi possível constatar sobre a realidade atual dos imóveis ociosos da Instituição, partindo de dois conceitos-chave: função social da cidade e da propriedade.

\section{Detalhando a ociosidade do patrimônio da UFRJ}

Preconizada na Constituição Federal de 1988 (arts. 5ํ, XXIII e 182) como conquista da luta pela Reforma Urbana; regulamentada pelo Estatuto da Cidade (Lei no 10.257/2001, arts. 1으, 2o e 39); presente no Código Civil (Lei no 10.257/2002, art. 2035, parágrafo único); e na Lei de Regularização Fundiária (Lei № 13.465, art. 10, VII), a função social da propriedade impõe ao proprietário - aqui defendido como público ou privado - o dever de dar ao imóvel uma finalidade que venha atender as finalidades socias das cidades: habitação, lazer, saúde, educação, geração de emprego e renda, mobilidade, proteção do meio ambiente etc. em prol da do bem coletivo, da segurança e do bem-estar dos cidadãos, bem como do equilíbrio ambiental, de acordo com as diretrizes do planejamento urbano expressos no Plano Diretor. ${ }^{6}$

Desta forma, quando um imóvel contraria os ditames constitucionais e infraconstitucionais urbanísticos ao não ser utilizado e/ou ocupado (vazio urbano), descumpre a função social da propriedade e da cidade. Este problema foi classificado no ordenamento jurídico em três categorias (Figura 2):

Figura 2. Classificação de vazios urbanos. Fonte: Cartilha da função social da propriedade - Prefeitura de São Paulo, 2015
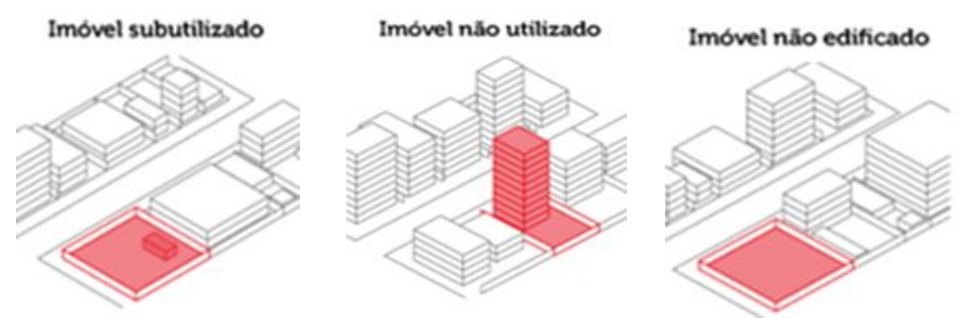

\footnotetext{
${ }^{6}$ Legislação municipal que ordena o uso e ocupação do solo no período de 10 anos. Obrigatório para cidades com mais de 20 mil habitantes (art. 182, da Constituição Federal).
} 
imóveis não utilizados (desafetados, sem uso total), em que, quando há o comprometimento do estado de conservação (imóvel em estado precário, em processo de arruinamento ou já em ruínas), configura-se o critério subjetivo ${ }^{7}$ do abandono. Do contrário, quando aparentemente o estado de conservação não torna o uso inviável, o imóvel é classificado como fechado (totalmente);

(ii) imóveis subutilizados, que ainda possuem uso e/ou ocupação, mesmo que parciais ou temporários, mas com parâmetros de aproveitamento inferiores aos definidos em lei (Plano Diretor). Pode haver, ou não, o comprometimento do estado de conservação do imóvel, porém, pelo uso parcial, só poderiam ser considerados como fechados parcialmente;

(iii) imóveis não edificados (totalmente desocupados, terrenos vazios), sem qualquer edificação, que também podem ser classificados como fechados ou abandonados (BORDE, 2006; SOUSA, 2010 apud JARDIM, 2018, p. 91).

A ociosidade imobiliária representa um relevante potencial fundiário ao planejamento urbano, principalmente nos grandes centros, mas recebe pouca ou nenhuma atenção dos poderes públicos, que, geralmente, relegam aos interesses do mercado o seu direcionamento.

A fim de contextualizar essa questão, apresenta-se os seguintes dados referentes ao âmbito da União realizados pelo do Ministério do Planejamento e apresentados por Odilla (2017): do total de 700 mil imóveis 10.304 eram ociosos, dos quais 8.242 (Figura 3) estavam no Brasil e disponíveis à negociação (venda, aluguel, cessão), sendo a maior parte (80\% aprox.) constituída de prédios comerciais, residências, salas, galpões e terrenos. Deste valor, (Figura 3), o Rio de Janeiro (1.587), o Pará (1.586) e a Bahia (1.012) concentravam 60\% do total

Figura 3. Distribuição de 8.242 imóveis ociosos da União disponíveis para negociação (2017). Fonte: Autores, 2019. Base de dados: Ministério do Planejamento, 2017.

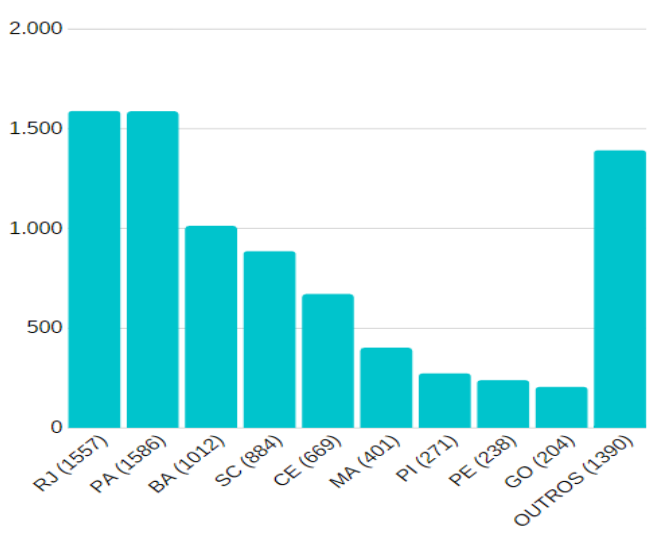

7 O critério objetivo para imóveis privados é a presença de 05 anos ou mais de débitos fiscais, conforme Código Civil e Lei de Regularização Fundiária. 
Os 2.062 restantes (20\% aprox.) representavam "bem de uso especial", com destinação específica para prestação de serviço público, como repartições, escolas e hospitais. Destes, a maior concentração estava presente em São Paulo (483), seguida do Mato Grosso do Sul (480) e Distrito Federal (165); 930 imóveis outros Estados e 04 em outros países (Figura 4).

Figura 4. Distribuição de 2.062 imóveis ociosos da União indisponíveis para negociação (2017). Fonte: Autores, 2019. Base de dados: Ministério do Planejamento, 2017

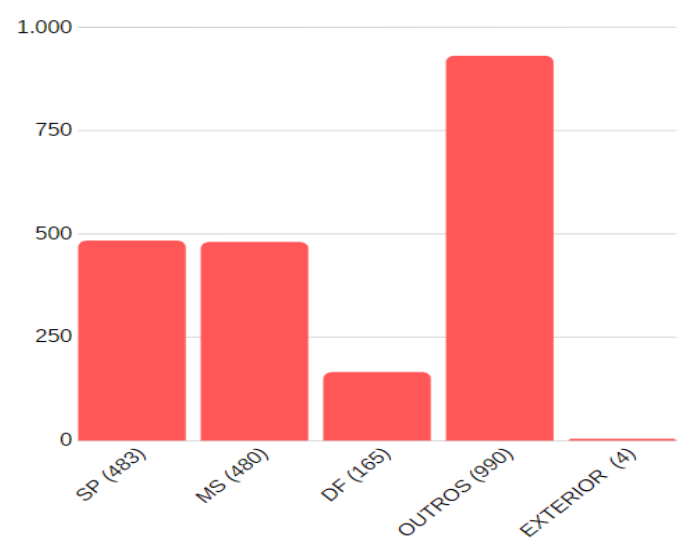

Com a utilização da ferramenta "Google Street View" a partir de imagens capturadas por satélite em 2017, foi possível identificar visualmente os imóveis ociosos da UFRJ apontados anteriormente e classificar o nível de ociosidade de cada um. Constatando-se, inicialmente, que a maioria desses bens possui edificação ainda que esta esteja contemplada apenas em parte do imóvel, ou mesmo consubstancie-se em estrutura móvel (contêiner) (Tabela 1).

Tabela 1. Uso e ocupação do solo dos 10 imóveis da UFRJ passíveis de financeirização Fonte: Autores, 2019; SCHIMIDT, 2018.

\begin{tabular}{|c|c|c|c|}
\hline IMÓVEL & USO & OCUPAÇÃO & ÁREA DO IMÓVEL $\left(\mathrm{m}^{2}\right)$ \\
\hline 1 & Subutilizado & Parcialmente edificado & $30 \mathrm{mil}$ \\
\hline 2 & $\begin{array}{c}\text { Subutilizado } \\
\text { (polo de Biotecnologia) }\end{array}$ & Parcialmente edificado & $105 \mathrm{mil}$ \\
\hline 3 & $\begin{array}{c}\text { Subutilizado } \\
\text { (estacionamento) }\end{array}$ & Parcialmente edificado & $9 \mathrm{mil}$ \\
\hline 4 & Área verde livre & Não-edificado & $40 \mathrm{mil}$ \\
\hline 5 & Campo de futebol & Não-edificado & $65 \mathrm{mil}$ \\
\hline 6 & $\begin{array}{c}\text { Subutilizado } \\
\text { (estacionamento) }\end{array}$ & Parcialmente edificado & $25 \mathrm{mil}$ \\
\hline 7 & Área verde livre & Não-edificado & $40 \mathrm{mil}$ \\
\hline 8 & Área verde livre & Não-edificado & $60 \mathrm{mil}$ \\
\hline 9 & Não-utilizado & Edificado & 832 \\
\hline 10 & Não-utilizado & Edificado & $55 \mathrm{mil}$ \\
\hline
\end{tabular}


Desses dez imóveis, merece destaque o antigo Canecão, casa de shows inaugurada em 1967 pela iniciativa privada que passou à administração da UFRJ em 2009, após longa disputa judicial. Em outubro de 2009 suas portas foram fechadas e assim permanece até hoje, com situação deplorável (Figura 5)

Figura 5. Parte interna do antigo Canecão (2016). Fonte: LUCENA, 2016.

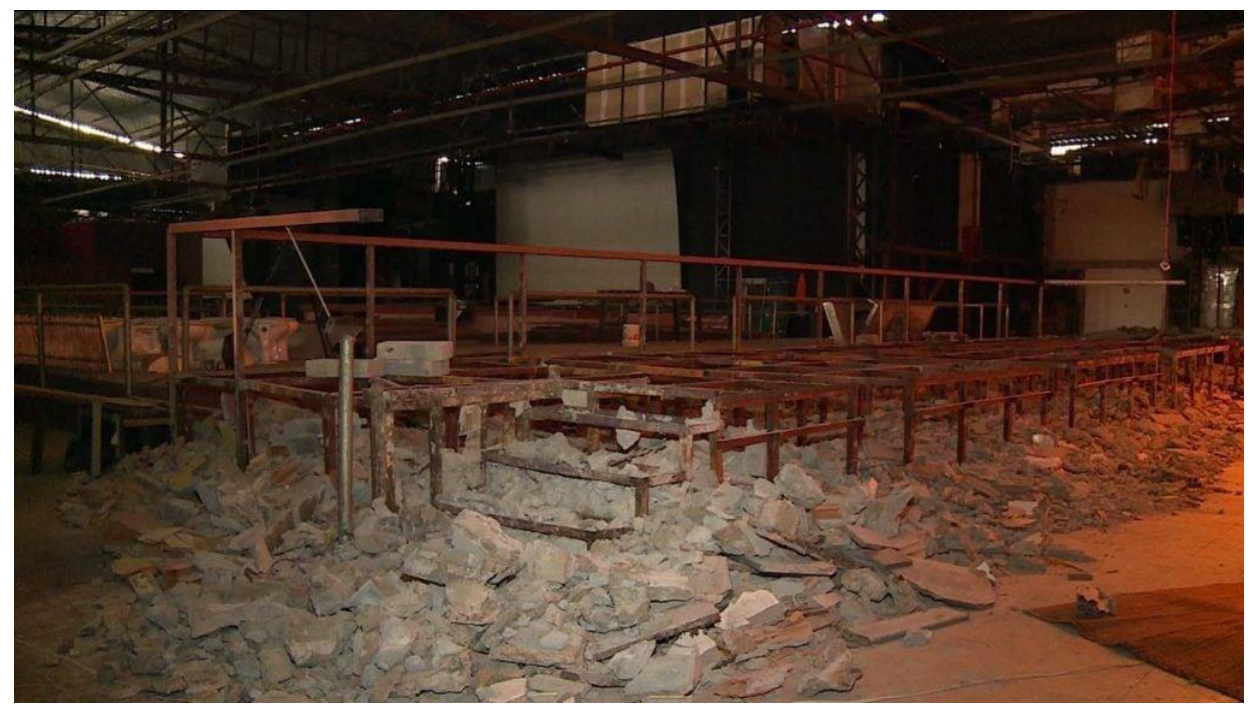

O equipamento guarda importância à história da cultura e arte do País, pois sediou a gravação de importantes shows, como: Maysa (1969), Chico Buarque, Vinícius de Moraes, Tom Jobim, Toquinho, Miúcha (1970), Chico Buarque e Maria Bethânia (1975), Elymar Santos (1985), Cazuza (1988), Roberto Carlos (1988) e O Grande Encontro (1996).

O imóvel, situa-se no bairro de Botafogo, área nobre da Cidade do Rio de Janeiro com ampla infraestrutura urbana, foi tombado em 1999 por iniciativa de lei estadual do então Dep. Sérgio Cabral. Esta proteção, no entanto, caiu em junho de 2019 com o objetivo de atender as demandas do mercado que há muito tempo pretende explorar esse espaço cultural, coadunado com a ideia de que o poder público tem o papel de promoção das condições que permitam a operação do mercado (ROLNIK, 2015, p. 133).

\section{CONSIDERAÇÕES FINAIS}

Nas três esferas políticas a ociosidade imobiliária é um fenômeno presente e com consequências negativas, nem sempre visíveis, para a vida social e das cidades, uma vez que, ao vulnerabilizar partes do tecido 
urbano facilita às várias facetas da lógica do planejamento capitalista ao espaço urbano, sendo a financeirização imobiliária apenas mais uma delas.

Essa dinâmica urbana reflete tanto a problematização levantada quanto o insolente desvio de finalidade que se acometeu à função social ao manipular o vazio urbano da universidade pública em prol do mercado.

Incluída nesta lógica está o aparelhamento patrimonial da educação superior, que há tempos sofre com a insuficiência de recursos, atualmente foi impulsionado pela política de austeridade imposta às universidades federais estimulando ainda mais a produção de vazios urbanos nos seus espaços e , com isso, visibilizando ao máximo essa precariedade fundiária, como observado no projeto piloto da UFRJ de outorga de concessão de uso e/ou constituição de fundo de investimento imobiliário de ativos imobiliários, inicialmente formado por 10 imóveis, que juntos somam cerca de 430 mil metros quadrados de ociosidade (imóveis não-edificados, subutilizados ou sem uso).

Destaca-se, neste processo, o patrimônio histórico, artístico e cultural do espaço de shows do antigo Canecão ao qual reserva-se um especial interesse, uma vez que, representa um excelente ponto à exploração econômica, que, inclusive, foi objeto de alteração legislativa determinando a retirada da inscrição de tombamento do imóvel, deixando-o livre de restrições administrativas para ingressar integralmente na lógica financeira.

Um ponto a ser sinalizado nesta dinâmica financeira é a contraprestação apresentadas pelo edital do BNDES que seria revertida em benefício da instituição de ensino, exclusivamente em equipamentos públicos, sem valores ou percentuais. Essa discrepância negocial destoa da necessidade de cobrir os recentes cortes de recursos sofridos pela UFRJ, reforçando a escassez de recursos necessários para a gestão universitária, de acordo com suas prioridades.

Essa construção restritiva deixa a desejar se comparado ao potencial fundiário que a instituição oferece. Fórmula como esta reflete a marca da lógica de mercado, e em razão disto, o planejamento urbano deve estar voltado para o seu potencial construído a fim de reconfigurá-lo em benefício do bem comum.

\section{REFERÊNCIAS}

BARREIRA, Gabriel. Alerj aprova destombamento do Canecão e abre caminho para concessão de espaço. O Globo, 04 jun. 2019. Disponível em: https://g1.globo.com/rj/rio-de-janeiro/noticia/2019/06/04/alerj-destomba-canecao-e-abre-caminho-paraprivatizacao-do-espaco.ghtml. Acesso em 07 set. 2019.

BNDES. Edital AARH № 31/2018. Pregão eletrônico disponível em: www.bndes.gov.br. 
FIX, Mariana de Azevedo Barreto. Financeirização e transformações recentes no circuito imobiliário no Brasil. Campinas. 2011. 288p. Tese (Doutorado, Economia) Universidade Estadual de Campinas, Instituto de Economia.

FRANZONI, Julia. Política urbana na ordem econômica. Revista Brasileira de Direito Municipal. Belo Horizonte: Fórum, 2013, p. 1346.

HARVEY, David; POTTER, Cuz. The right to the Just City. In: MARCUSE, P. et al. Searching for the just city. Londres, Nova York: Routledge, 2009.

JARDIM, Felipe. IPTU progressivo no tempo ou arrecadação de bem vago abandonado?: aplicabilidade de instrumentos jurídicourbanísticos em imóveis ociosos do bairro do Recife. 2019. 194p. Dissertação (Mestrado). Programa de Pós-graduação em Desenvolvimento Urbano. Centro de Artes e Comunicação. Universidade Federal de Pernambuco. Recife, 2019. Disponível em: https://repositorio.ufpe.br/handle/123456789/32193. Acesso em 08 set. 2019.

LUCENA, Felipe. História do Canecão. Diário do Rio. 04 out. 2016. Disponível em: https://diariodorio.com/historia-do-canecao/. Acesso em 13 set. 2019.

MARICATO, Ermínia. O impasse da política urbana no Brasil. Petrópolis: Vozes, 2011.

ODILLA, Fernanda. Mesmo com mais de 10 mil imóveis vazios, governo gasta 1,6 bi com aluguel. BBC Brasil, 27 out. 2017. Disponível em: https://www.bbc.com/portuguese/brasil-41719519. Acesso em 07 set. 2019.

PEREIRA, Alvaro L. dos Santos. Intervenções em centros urbanos e conflitos distributivos: modelos regulatórios, circuitos de valorização e estratégias discursivas. Tese (doutorado) - Faculdade de Direito, Universidade de São Paulo. São Paulo. 2015.

POLANYI, Karl. The great transformation: the political and economic origins of our time. Nova York: Farrar e Rinehart, 1994.

ROLNIK, R. Guerra dos Lugares: a colonização da terra e da moradia na era das finanças. São Paulo: Boitempo, 2015.

ROYER, Luciana. Financeirização da política habitacional: limites e perspectiva. Tese (Doutorado) - Faculdade de Arquitetyra e Urbanismo de São Paulo. São Paulo. 2012.

SANFELICI, Daniel. A Metrópole sob o ritmo das finanças: implicações socioespaciais da expansão imobiliária no Brasil. Tese (Doutorado) Faculdade de Filosofia, Letras e Ciências Humanas, Universidade de São Paulo. São Paulo. 2013.

SCHIMIDT, Selma. UFR tem pelo menos $\mathbf{4 3 0}$ mil metros quadrados em terrenos e prédios subaproveitados e ociosos pelo Rio. 0 GLOBO: Rio, 10 set. 2018. Disponível em: https://oglobo.globo.com/rio/ufrj-tem-pelo-menos-430-mil-metros-quadrados-emterrenos-predios-subaproveitados-ociosos-pelo-rio-23055609. Acesso em 07 set. 2019 